\title{
Advances in Neotropical Myrmecology
}

\author{
Jacques Hubert Charles Delabie, ${ }^{1}$ Fernando Fernández, ${ }^{2}$ and Jonathan Majer ${ }^{3}$ \\ ${ }^{1}$ Laboratório de Mirmecologia, Convênio CEPLAC-UESC, Centro de Pesquisa do Cacau, CP 7, 45500-000 Itabuna, BA, Brazil \\ ${ }^{2}$ Instituto de Ciencias Naturales, Universidad Nacional de Colombia, Carrera 30 No. 45-03, Bogotá, Colombia \\ ${ }^{3}$ Curtin Institute for Biodiversity and Climate, Curtin University, P.O. Box U1987, Perth, WA 6845, Australia \\ Correspondence should be addressed to Jacques Hubert Charles Delabie, jacques.delabie@gmail.com
}

Received 30 November 2011; Accepted 30 November 2011

Copyright () 2012 Jacques Hubert Charles Delabie et al. This is an open access article distributed under the Creative Commons Attribution License, which permits unrestricted use, distribution, and reproduction in any medium, provided the original work is properly cited.

\begin{abstract}
... I believe Myrmecology is even more significant for tropical ecology than Ornithology, because the impact of ants in tropical habitats is tremendous. In addition ants served for many disciplines as model systems, for example, Sociobiology, Communication Biology, Chemical Ecology, and in recent years ants and other social insects have become model organisms for the study of Epigenetics ... (Bert Hölldobler in a message sent to the organizers of the XX Simpósio de Mirmecologia (2011) which was held at Petrópolis, Brazil)
\end{abstract}

Knowledge about Neotropical ants began to accumulate ever since European colonization, when the Portuguese owner of a sugarcane factory in the Reconcavo region of Bahia, Brazil, Gabriel Soares de Souza in 1587 [1] and the Spaniard José Celestino Mutis in 1780s [2,3] made the first observations about ants in their American habitats. These observations were soon followed by more texts published by naturalist travelers in the XIX Century reporting ant behavior, among whom Bates [4] is one between the best known. Myrmecology as a discipline of entomology took its roots when these travelers and a myriad of correspondents distributed throughout the American continent sent biological material to European collections where taxonomists such as Auguste Forel, Carlo Emery, or Felix Santschi could study and describe considerable amounts of new ant material [5]. In the meantime, Forel, Santschi (as Forel's secretary), and Edouard Bugnion (Forel's brother-inlaw) made a memorable travel (1896) through the Sierra
Nevada de Santa Marta region in the northeast of Colombia, where they subsequently accumulated ant observations and experiences which they will use throughout their lives. Interestingly, all the three produced independent memories of the Colombian expedition $([6,7]$, Santschi's notes in [8]). Other important contributors to earlier Neotropical myrmecology in the XIX and XX centuries were the German mycologist Alfred Möller in southern Brazil and Franciscan priests Thomas Borgmeier and Walter Kempf; the Brazilians Herman Luederwaldt, Karol Lenko, Mario Autuori, Elpídio Amante, and Cincinnato Rory Gonçalves; the Argentineans Carlos Bruch, Angel Gallardo, and Nicolas Kusnezov; and the North Americans William M. Mann, Neal Albert Weber, and William Morton Wheeler [9-14]. Research output from the Neotropical Region still remained modest until the Second World War. This began to change with the rapid development of national infrastructures that started to occur in the 1960 s and the burgeoning of new universities in the 1970s and 1980s. Most of the older scientific contributions were historically devoted to taxonomy and leaf-cutter ant damage and control, but the topics which have called the attention of myrmecologists in recent years have been much more diverse and concerned essentially with ant communities, antplant relations, mutualisms, biomonitoring, biogeography, morphology and anatomy, genetics and cytogenetics, and taxonomy.

Selection of exculsive identifiers for publications from the Neotropics makes it difficult to measure output from publication databases, but taking leaf cutter ants as a surrogate, and using key words Acromyrmex, Atta, or Attini, as search identifiers in the ant database Formis 2011 [15], 


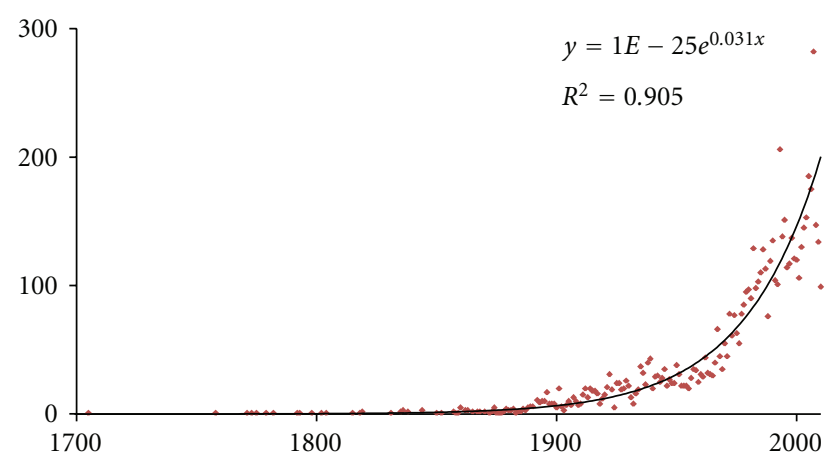

Figure 1: The exponential spread of papers containing the words Acromyrmex, Atta, or Attini in the title, abstract, or key words $(n=$ $6,561)$. The regression is calculated for the period from 1850-2010. Although the tribe is not exclusively Neotropical, we estimate an annual output of 300 leaf-cutter ants papers by 2020. Formis 2011 [15].

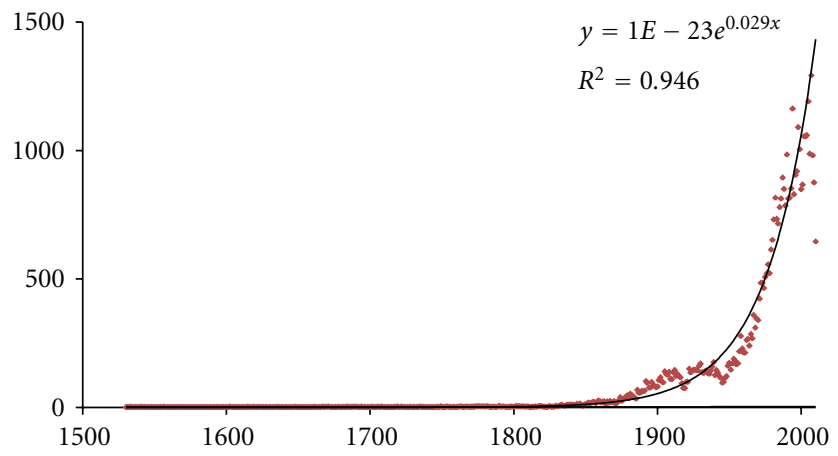

FIgURE 2: The exponential spread of World ant literature $(n=$ $46,182)$. The regression is based on annual production and is calculated for the period between 1800 and 2010. An extrapolation estimates to 1,700 for the number of projected papers on ant biology for 2020. Formis 2011 [15].

indicates an almost exponential increase in output from Latin America during the latter part of the last century through to the present time (Figure 1). This pattern closely follows World trends (Figure 2) and, assuming that for every paper published on leaf cutter ants, another four to six papers are currently produced on other Neotropical ant species, the Latin American ant literature could soon account for one third of annual World ant literature. So great is this increase, that extrapolation suggests an annual output of 1700 papers (World lower estimation) per year by the time of 2020 . This enthusiasm for ants is matched by the existence of a Latin American Sections of the International Union for the Study of Social Insects, and also by a very attractive biennual Simpósio de Mirmecologia, which is traditionally attended by hundreds of scientists and students from Brazil and, in the recent years, by an increasing number of scientists from elsewhere in the Americas, Europe, and Australia.

This volume brings together some of the recent research on ants in the Neotropical Region and includes contributions by authors from Argentina, Australia, Belgium, Brazil, Colombia, Costa Rica, Ecuador, France, French Guiana,
Mexico, Venezuela, and USA. Six of the contributions are concerned with taxonomy and systematics of the ant fauna and reflect the spread of interest in ant taxonomy and the new integrative taxonomy approach [16]. One is concerned with ant morphology and continues the long tradition in Brazil of identifying special features within local ants. A further three papers address aspects of ant biology, including division of labour, chemical recruitment, and behavioural differentiation between castes, with emphasis on reproduction.

Three of the papers are concerned with the ecology of individual species, while a further five take a community ecology approach to the fauna. In addition, since the Neotropics contain some of the World's biodiversity hotspots, five other papers describe various aspects of the interactions between ants and some of the unique plant species which occur in this region. There is one paper on leaf cutter ants which, interestingly, indicates that leaf cutting activity can influence the local spread of fire in Amazon ecosystems.

The influence of the ALL protocol [17] and the use of Winkler sampling in studies of community ecology are evident in some of the papers, although one contribution discusses the potential for a new sampling method, subterranean trapping, to augment existing techniques. Finally, the use of ants as bioindicators, originally pioneered in Australia [18], has escalated throughout countries in the Neotropical Region, and one paper reviews such studies in Brazil, presenting ideas for improvements to the procedure.

Perusal of the papers in this volume, and those elsewhere, indicates that a sizeable proportion of Neotropical ant species have yet to be described, and researchers in these groups tend to assign ants to morphospecies; they may even use morphospecies codes for described species if they do not have ready access to the main museums where reference collections are held. This unsatisfactory situation is confounded by the fact that each research group tends to adopt its own morphospecies coding system, or even a separate coding system for each individual study! Thus we have endless papers featuring Pheidole sp. 1, Pheidole sp. 2, and Pheidole sp. 3, but we have no idea whether they are the same species or not.

This imposes serious limitations for the making of comparisons between studies - a lost opportunity indeed. It is a relatively simple matter to determine an ant to genus level and assign codes to perceptibly different morphospecies, but obtaining determinations requires access to keys, museums, or specialists, and producing a uniform morphospecies coding system requires a system of voucher specimens, deposited in secure and accessible locations, which is a requirment to be inserted in "material and methods" by many of the entomological journals. All of this takes time and money.

What can we do to overcome this impediment? We suggest that each of the major countries have at least one, and preferably more, central reference collections, comprising formally determined material plus vouchers of coded morphospecies, all compiled using a standardised numbering and data-based system. Attempts should be made to "clone" these collections, or at least regional subsets of the material, 
and placing the subcollections in strategic regions of the country where they are accessible to local research groups. As an adjunct to this, keys to the material should be produced, illustrated with line drawings or photographs, and rapidly made available on the internet. The existence of undescribed "morphospecies" need be no bar to the production of keys. Heterick's [19] recent book A guide to the Ants of SouthWestern Australia features keys and line diagrams of the 500 or so species which exist there, of which almost half are only known by morphospecies codes. We admit that coordination of collections from the various research groups would be an enormous task, especially if cross-national coordination was involved. At the very least, integrated collections for each country could be assembled, with each having a prefix letter before the code number (e.g., Pheidole sp. B1, Pheidole sp. B2, and Pheidole sp. B3, etc. for Brazil, e.g.). Subsequent integration of the national collections, at least for individual genera, could then be undertaken as specialist projects or could be coordinated through organized groups, possibly under the direction of the International Union for the Study of Social Insects (IUSSI).

To assemble these "national" collections and keys would require dedicated staff, a committed and guaranteed amount of resources, with security of tenure. However, considering the importance of ants in our natural and cultural landscapes, and their increasing importance in the disciplines linked to Neotropical entomology as a whole, this might well be a good investment. Major research organisations, governments, and national or international philanthropic funding bodies should seriously consider this option. An embryo of this effort is the site http://www.antweb.org/ maintained by the Californian Academy of Sciences, which has the explicit mission of documenting, through high-quality imagery, the whole ant diversity of the Planet, beginning with the types. Besides offering the option of "digital curation" for countries or areas, initiatives like this can encourage taxonomists to have consensus on the delimitation of morphospecies of large or problematic genera, together with the well-known genera with broad morphological variation. It is critical that the few researchers with access to types can offer high-quality photos of them, in order to assist those who have to rely less on loans and risky mail.

The numerous internet sites which currently exist about ants, specialized symposia, ant field courses, and many other activities clearly show that the tropical myrmecology lives a golden era with a very promising future.

\section{Acknowledgments}

The authors would like to thank Donat Agosti, Joe Cora, Jacques Forel, Norm Johnson, Bert Hölldobler, and Sanford Porter who assisted in various ways, along with the numerous anonymous referees. J. Delabie is supported by the FAPESB/CNPq project PNX001/2009 and a research grant by CNPq.

Jacques Hubert Charles Delabie Fernando Fernández Jonathan Majer

\section{References}

[1] K. Lenko and N. Papavero, Insetos no Folclore, Plêiade e FAPESB, São Paulo, Brazil, 2nd edition, 1996.

[2] F. Fernández and E. O. Wilson, "José Celestino Mutis, the ants and Pheidole mutisi sp nov.", Revista Colombiana de Entomología, vol. 34, no. 2, pp. 203-208, 2008.

[3] E. O. Wilson and J. M. Gómez Durán, Kingdom of Ants, José Celestino Mutis and the Dawn of Natural History in the New World, The Johns Hopkins University Press, Baltimore, Md, USA, 2010.

[4] H. W. Bates, The Naturalist on the River Amazons, vol. 2, John Murray, London, UK, 1863.

[5] D. Agosti and N. F. Johnson, "La nueva taxonomía de hormigas," in Introducción a las Hormigas de la Región Neotropical, F. Fernández, Ed., pp. 45-48, Instituto de Investigación de Recursos Biológicos Alexander von Humboldt, Bogotá, Colombia, 2003.

[6] E. Bugnion, "A. Forel. Souvenirs myrmécologiques recueillis," Mitteilungen der Schweizerischen Entomologischen Gesellschaft, vol. 15, pp. 156-193, 1931.

[7] A. Forel, Mémoires, Neuchatel, 1941.

[8] D. Chérix and M. Sartori, "A propos de Félix Santschi (18721940)," Bulletin Romand d'Entomologie, vol. 6, pp. 45-86, 1986.

[9] A. Möller, "As hortas de fungo de algumas formigas sulamericanas," Revista de Entomologia, supplement 1, pp. 1122, 1941, translated by A. P. Viégas \& E. M. Zink from the German 1893 original edition in Botanische Mitteilungen aus den Tropen, Jena.

[10] W. W. Kempf, "Father Thomas Borgmeier, O. F. M. (18921975) in memoriam," Studia Entomologica, vol. 19, pp. 1-37, 1976.

[11] N. Kusnezov, Hormigas Argentinas_Claves para su Identificación, vol. 2, Fundación Miguel Lillo, Tucuman, Argentina, 1978.

[12] H. S. Lopes, "Frei Walter entomólogo," Studia Entomologica, vol. 20, pp. 3-15, 1978.

[13] A. Neiva, Esboço Histórico Sobre a Botânica e Zoologia no Brasil, UNB, Brasília, Brazil, 1989.

[14] C. R. F. Brandão, "Avanços da mirmecologia no Brasil," $O$ Biológico, vol. 69, pp. 1-3, 2007.

[15] FORMIS, "FORMIS: A Master Bibliography of Ant Literature," EndNote Versions 8-13, compilation by D. P. Wojcik \& S. D. Porter, 2011, http://www.ars.usda.gov/saa/cmave/ifahi/ formis.

[16] B. C. Schlick-Steiner, F. M. Steiner, B. Seifert, C. Stauffer, E. Christian, and R. H. Crozier, "Integrative taxonomy: a multisource approach to exploring biodiversity," Annual Review of Entomology, vol. 55, pp. 421-438, 2010.

[17] D. Agosti, J. Majer, E. Alonso, and T. Schultz, Ants: Standard Methods for Measuring and Monitoring Diversity, Biological Diversity Handbook Series, Smithsonian Institution Press, Washington, DC, USA, 2000.

[18] A. N. Andersen and J. D. Majer, "Ants show the way down under: invertebrates as indicators in land management," Frontiers in Ecology and the Environment, vol. 2, pp. 291-298, 2004.

[19] B. E. Heterick, "A guide to the ants of South-western Australia," Records of the Western Australian Museum, supplement 76, pp. 1-206, 2009. 

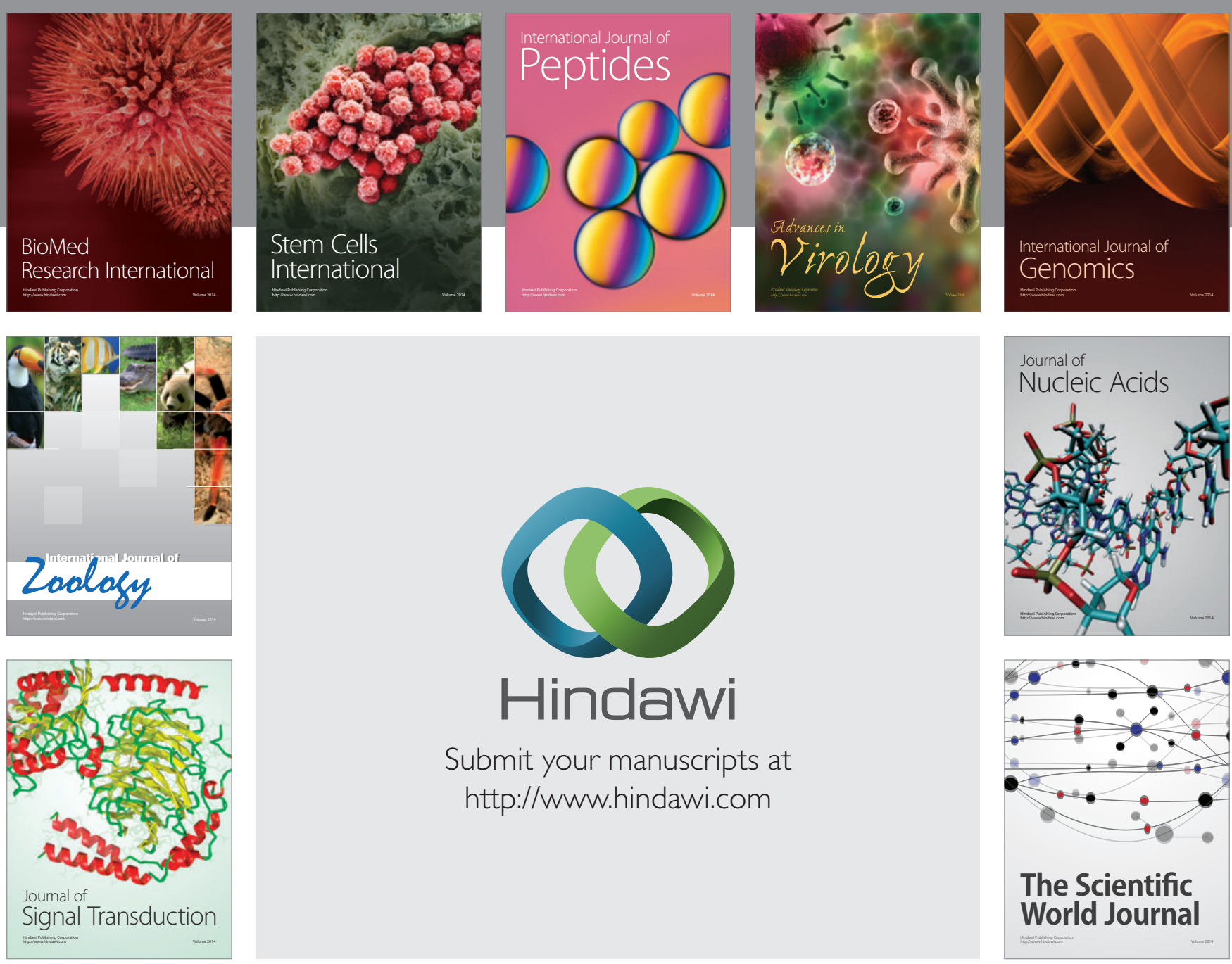

Submit your manuscripts at

http://www.hindawi.com
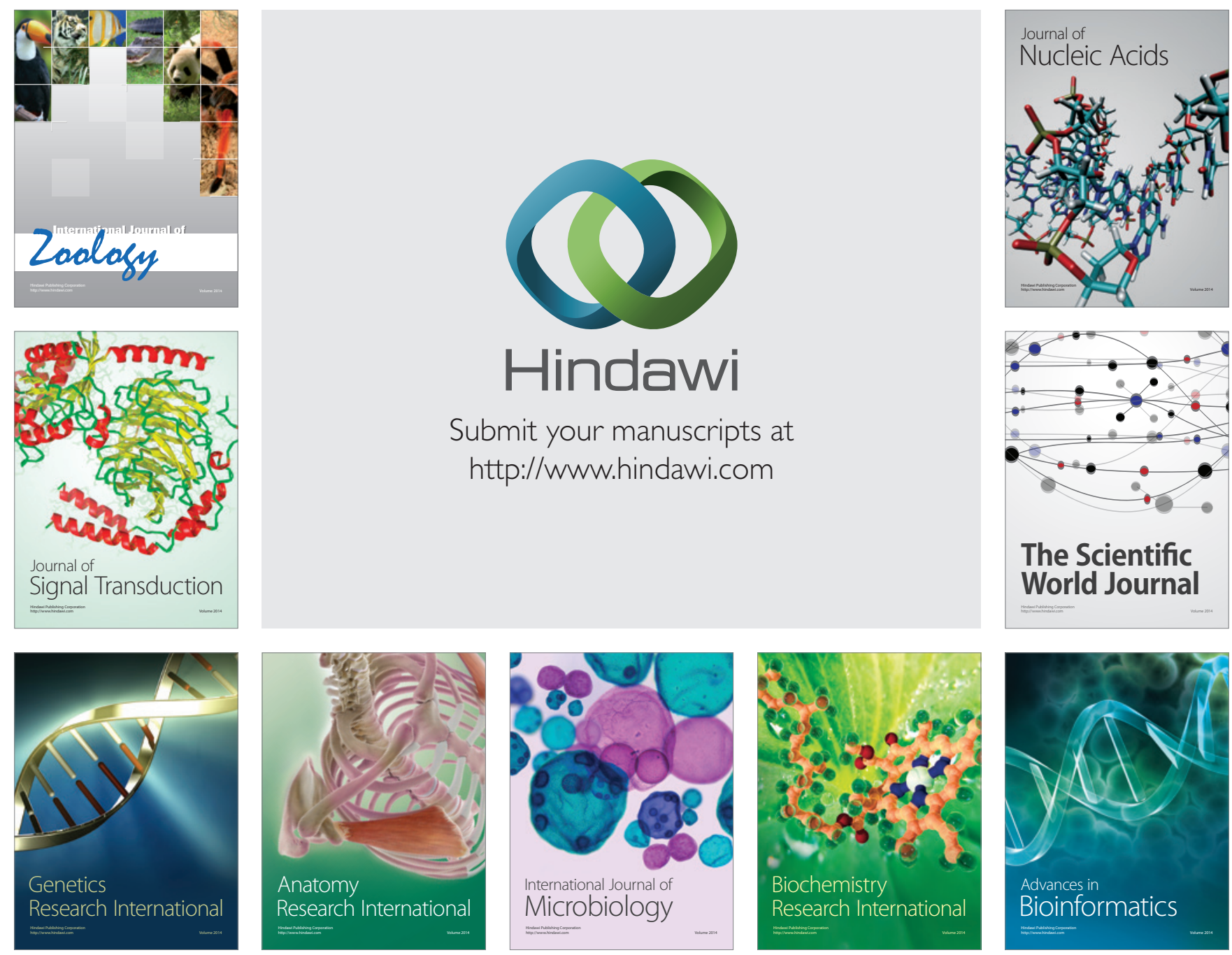

The Scientific World Journal
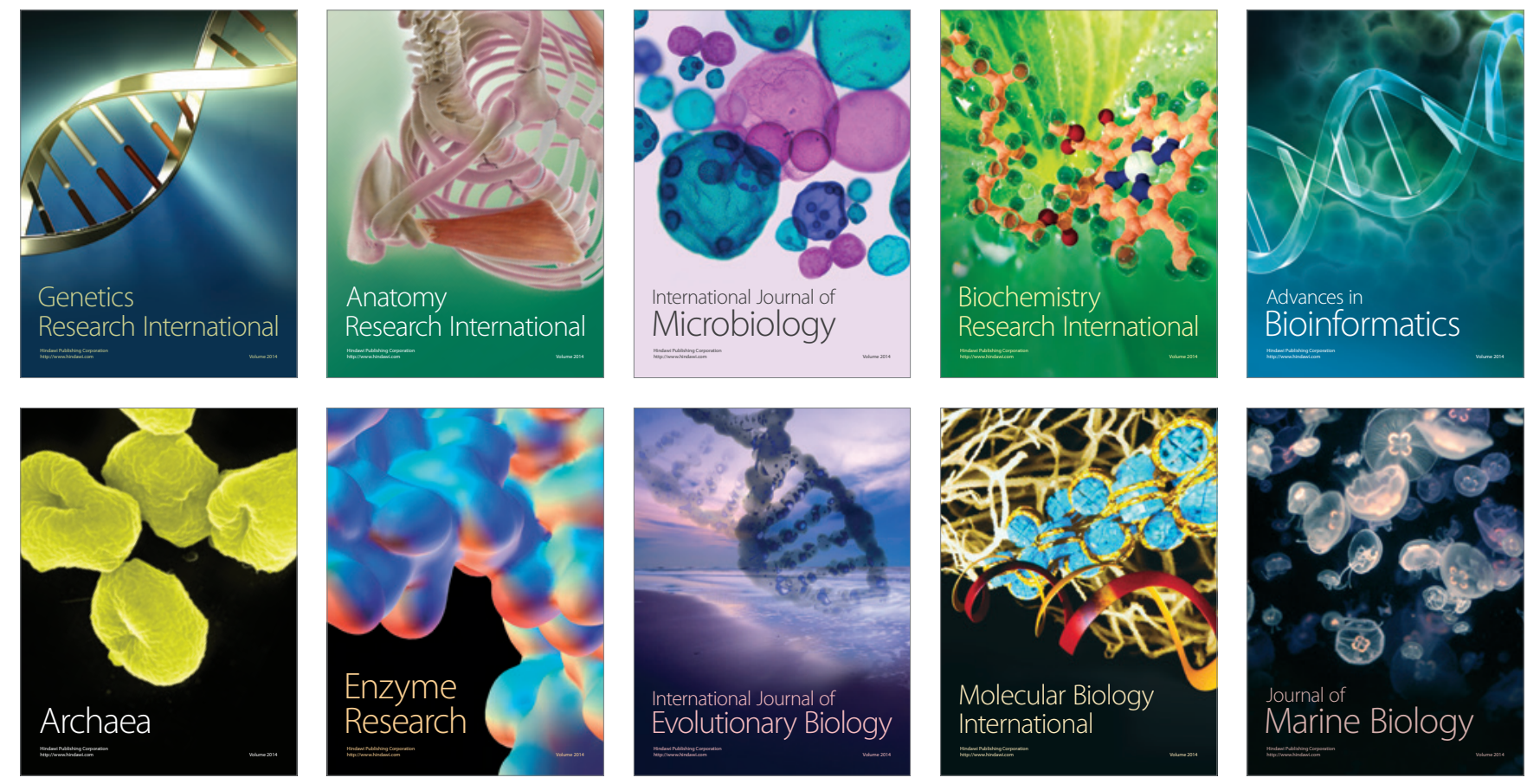